\title{
Development of a SNP linkage map and genome-wide association study for resistance to Aeromonas hydrophila in pacu (Piaractus mesopotamicus)
}

Vito A. Mastrochirico-Filho ${ }^{1}$, Carolina H. S. Borges ${ }^{1}$, Milena V. Freitas ${ }^{1}$, Raquel B. Ariede ${ }^{1}$, Fabiana Pilarski ${ }^{1}$, Ricardo Utsunomia ${ }^{2}$, Roberto Carvalheiro ${ }^{3,4}$, Alejandro P. Gutierrez ${ }^{5}$, Carolina Peñaloza ${ }^{5}$, José M. Yáñez Ross D. Houston ${ }^{5}$ and Diogo T. Hashimoto ${ }^{1 *}$ (D)

\begin{abstract}
Background: Pacu (Piaractus mesopotamicus) is one of the most important Neotropical aquaculture species from South America. Disease outbreaks caused by Aeromonas hydrophila infection have been considered significant contributors to the declining levels of pacu production. The current implementation of genomic selection for disease resistance has been adopted as a powerful strategy for improvement in fish species. This study aimed to investigate the genetic architecture of resistance to A. hydrophila in pacu via Genome-Wide Association Study (GWAS), the identification of suggestive Quantitative Trait Loci (QTLs) and putative genes associated with this trait. The genetic data were obtained from 381 juvenile individuals belonging to 14 full-sibling families. An experimental challenge was performed to gain access to the levels of genetic variation for resistance against the bacteria using the following trait definitions: binary test survival (TS) and time of death (TD).

Results: The analyses of genetic parameters estimated moderate heritability $\left(h^{2}\right)$ for both resistance traits: $0.20( \pm$ 0.09 ) for TS and 0.35 ( \pm 0.15) for TD. A linkage map for pacu was developed to enable the GWAS, resulting in 27 linkage groups (LGs) with 17,453 mapped Single Nucleotide Polymorphisms (SNPs). The length of the LGs varied from 79.95 (LG14) to 137.01 (LG1) cM, with a total map length of 2755.60 cM. GWAS identified 22 putative QTLs associated to A. hydrophila resistance. They were distributed into $17 \mathrm{LGs}$, and were considered suggestive genomic regions explaining $>1 \%$ of the additive genetic variance (AGV) for the trait. Several candidate genes related to immune response were located close to the suggestive QTLs, such as tbk1, trim16, I112rb2 and lyz2.

Conclusion: This study describes the development of the first medium density linkage map for pacu, which will be used as a framework to study relevant traits to the production of this species. In addition, the resistance to $A$. hydrophila was found to be moderately heritable but with a polygenic architecture suggesting that genomic selection, instead of marker assisted selection, might be useful for efficiently improving resistance to one of the most problematic diseases that affects the South American aquaculture.
\end{abstract}

Keywords: Motile Aeromonas septicemia, Disease outbreaks, Resistance QTLs, Fish farming

\footnotetext{
* Correspondence: diogo.hashimoto@unesp.br

'São Paulo State University (Unesp), Aquaculture Center of Unesp, Via de Acesso Prof. Paulo Donato Castellane, s/n, Jaboticabal, SP 14884-900, Brazil

Full list of author information is available at the end of the article
}

(c) The Author(s). 2020 Open Access This article is licensed under a Creative Commons Attribution 4.0 International License, which permits use, sharing, adaptation, distribution and reproduction in any medium or format, as long as you give appropriate credit to the original author(s) and the source, provide a link to the Creative Commons licence, and indicate if changes were made. The images or other third party material in this article are included in the article's Creative Commons licence, unless indicated otherwise in a credit line to the material. If material is not included in the article's Creative Commons licence and your intended use is not permitted by statutory regulation or exceeds the permitted use, you will need to obtain permission directly from the copyright holder. To view a copy of this licence, visit http://creativecommons.org/licenses/by/4.0/ The Creative Commons Public Domain Dedication waiver (http://creativecommons.org/publicdomain/zero/1.0/) applies to the data made available in this article, unless otherwise stated in a credit line to the data. 


\section{Background}

Bacterial diseases are responsible for the loss of billions of dollars to aquaculture production every year, and may be considered a major threat to the fish farm's sustainability [1, 2]. Motile Aeromonas septicemia is a common infectious disease in aquaculture caused by Aeromonas hydrophila, a gram-negative bacterial pathogen, which is generally associated with symptoms such as reddened or rotten fins, external/internal septicemia, and hemorrhage of aquatic organisms [3].

The incidence of sanitary problems associated to the intensification of fish production have caused large mortalities by $A$. hydrophila infection that involves important farmed fish species from South America, such as pacu (Piaractus mesopotamicus) [4, 5]. Although there are no official statistics about the economic losses related to mass mortalities caused by A. hydrophila outbreaks at the pacu farms, nonofficial communications of Brazilian farmers have reported that $A$. hydrophila infection is responsible for total mortalities ranging between 20 to $30 \%$ of the annual production [6].

While practically all Neotropical fish production is still carried out based on unselected stocks, large-scale genetic studies performed on global aquaculture species, such as carp [7-9], tilapia [10] and salmonids [11-13] have highlighted major possibilities to improve resistance to infectious diseases by selective breeding. In contrast, selective breeding for disease resistance is challenging because this trait is difficult to measure directly on selection candidates $[14,15]$. While major QTLs affecting disease resistance have been identified in some studies [16, 17], such traits typically exhibit a polygenic architecture. As such, it is preferable to have a dense genetic marker panel containing thousands of SNPs to combine linkage analysis and GWAS, in order to detect QTLs and identify candidate genes that are linked to the disease resistance trait $[18,19]$. Current advances in understanding the genetic architecture of resistance against A. hydrophila by GWAS-based conclusions have already been performed in some fish species, including carp Labeo rohita [20] and catfish hybrids between Ictalurus species [21]. In both studies, several significantly associated QTLs to resistance against $A$. hydrophila were identified, containing candidate genes related to the immune responses.

Experimental challenges that consisted of an infection induced on pacu families have shown significant genetic variation for resistance against $A$. hydrophila when binary survival status and time of death were used as trait definitions, which have demonstrated the potential of the genetic improvement for Aeromonas resistance in this species [6]. However, GWAS analyses to understand the genomic basis of resistance to $A$. hydrophila have not yet been performed in pacu. Moreover, there is neither a dense SNP platform nor a genetic map available to perform GWAS analyses in pacu. Based on this proposal, restriction site-associated DNA sequencing (RADSeq) represents an affordable and viable technique for the discovery and genotyping of several sets of SNPs, through a reduced representation of the genome belonging to multiplexed libraries of samples [22-24], particularly for non-model species without reference genome, such as pacu.

The present study aimed for the discovery and the genotyping of SNPs using RAD-Seq approach on 14 fullsib pacu families, which had been experimentally challenged with $A$. hydrophila infection. These data were used to investigate the genetic architecture of resistance to this disease generating a medium density linkage map and GWAS analyses for host resistance, following survival and time of death as trait definitions. The presented results will be fundamental to evaluate the potential of genome-wide molecular information for obtaining subsidies on application of genetic selection studies aiming at resistance against $A$. hydrophila, and accelerating the genetic improvement of this trait on pacu aquaculture.

\section{Results \\ Genetic parameter analysis}

Before the challenge, all fish were healthy without any symptom of infection. Nevertheless, the presence of bacterial infection was checked in a random subsample by routine microbiological investigation. During the challenge test, susceptible individuals demonstrated lethargic behavior, erratic swimming and red spotted skin lesions over the operculum, head, fins and gills. No symptoms associated with infection were reported in individuals belonging to the unchallenged control group. High mortality rates were observed mainly at the second day after inoculation (Fig. 1). Considering the 381 challenged individuals, the total cumulative mortality rate at the end of the test period was $72.3 \%$ (277 individuals) across all the families. The cumulative mortality rate of the most susceptible family to $A$. hydrophila infection was $93.1 \%$ (family 1); in contrast, the most resistant family presented $40.7 \%$ of cumulative mortality rate (family 14), which indicated a considerable phenotypic variation associated to resistance against $A$. hydrophila infection (Fig. 1).

Additive-genetic variation was observed in both traits. Variance components and estimated heritabilities for TS and TD are presented in Table 1 . The results registered moderate heritability values for $A$. hydrophila resistance in this experimental population of pacu, which were estimated in $0.20( \pm 0.09)$ and $0.35( \pm 0.15)$ for TS and TD, respectively. Heritability using the genomic information 


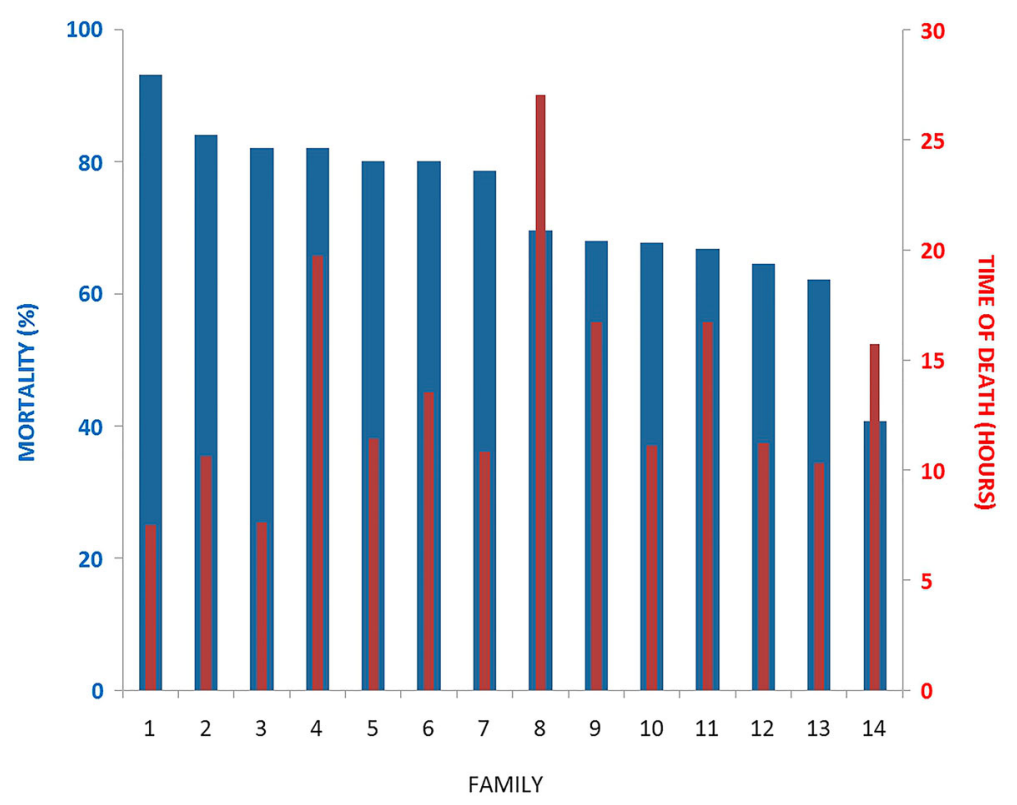

Fig. 1 Mortality rate (\%) and time of death (hours) of 14 pacu (P. mesopotamicus) families infected with A. hydrophila during 14-day resistance challenge. Blue columns represent mortality rates (\%) for each family, whereas red columns represent the average time of death (hours) corresponding for each family

was similar to the pedigree-based results (data not shown).

\section{Identification of SNPs from RAD-Seq technology}

Initially, 1,599,222,848 RAD-Seq reads with $150 \mathrm{bp}$ were obtained. From the total, 795,613 low quality reads were excluded of the analysis. Additionally, 984,501,898 ambiguous barcodes and 11,344,436 ambiguous RAD tags were discarded, which resulted in 602,580,901 retained reads.

The average number of putative RAD loci identified for each family ranged from 37,035.12 (SD 4657.77) to 31,382.57 (SD 6664.41), with an average coverage ranging from 19x (SD 8x) to 25x (SD 15x). A catalog containing 246,566 consensus loci was created, of which 26, 597 polymorphic loci with 162,305 SNPs were obtained. Only 30,093 SNPs presenting MAF values higher than 0.05, and on Hardy-Weinberg equilibrium were retained.

Table 1 Estimates of additive genetic variance $\left(\sigma_{a}^{2}\right)$, residual variance $\left(\sigma_{e}^{2}\right)$, phenotypic variance $\left(\sigma_{p}^{2}\right)$ and heritability $\left(h^{2}\right)$ for resistance to $A$. hydrophila in pacu (P. mesopotamicus), measured as test survival (TS) and time of death (TD). Standard error in parenthesis

\begin{tabular}{lll}
\hline Variance components & TS & TD \\
\hline$\sigma_{a}^{2}$ & $0.25(0.14)$ & $0.82 \times 10^{6}\left(0.42 \times 10^{6}\right)$ \\
$\sigma_{e}^{2}$ & 1 & $0.15 \times 10^{7}\left(0.26 \times 10^{6}\right)$ \\
$\sigma_{p}^{2}$ & $1.25(0.14)$ & $0.23 \times 10^{7}\left(0.25 \times 10^{6}\right)$ \\
$h^{2}$ & $0.20(0.09)$ & $0.35(0.15)$ \\
\hline
\end{tabular}

SNPs that exceeded $20 \%$ of missing genotype data were also removed, leaving 18,262 SNPs for downstream analyses. Furthermore, 46 individuals exceeded $30 \%$ of missing genotype data and were discarded, which resulted in 345 individuals for a correct assignment of true parents.

\section{Parentage assignment}

The pedigree information provided by the SNP data was tested for each individual to confirm a correct parental assignment. Considering the genotype errors found, it was not possible to obtain a conclusive analysis in 13 individuals due to the lack of statistical criteria (low likelihood ratio) and, therefore, were disregarded. Additionally, Mendelian rate test was carried out in the offspring to discard alleles that could not have been received them from their putative biological parents. Then, this analysis discarded 300 SNPs with more than $10 \%$ of Mendelian error rate, remaining 17,962 SNPs to be included in the linkage map.

\section{Linkage map and synteny analysis}

As pacu has 27 pairs of chromosomes $(2 \mathrm{n}=54), 17,453$ SNPs were assigned to 27 linkage groups. Initially, 652 SNPs presented none association to any linkage group. Posteriorly, 143 markers were joined to already existing linkage groups, and 509 markers were discarded because no association to the linkage map was detected.

To produce the linkage map, the OrderMarkers 2 module was repeated 5 times retaining the ordering with the highest likelihood for each linkage group. The marker 
orders with the highest likelihoods for each linkage group were combined to produce the final linkage map. In the ordering of markers, the number of SNPs varied from 262 (LG27) to 1504 (LG1) (Fig. 2).

The length of linkage groups varied from 79.95 (LG14) to 137.01 (LG1) cM, with a total integrated map length of $2755.60 \mathrm{cM}$ and an average distance between markers of $0.47 \mathrm{cM}$. Considering the density within linkage groups, the linkage group that presented the highest and lowest density of markers were LG8 and LG24, with an average distance of markers of 0.38 and $0.66 \mathrm{cM}$, respectively (Fig. 2).

Conserved genomic synteny between pacu and the blind cave tetra (Astyanax mexicanus) species was investigated using all mapped loci on the LGs (10,220 loci). Significant BLASTn hits to blind cave tetra genome matched 2851 pacu RAD tags (27.9\%) wherein 2194 (21.5\%) showed synteny for all 27 linkage groups (Fig. 3). Despite the small percentage of alignments to the blind cave fish genome, a high level of genomic synteny was observed between pacu and this model species. The number of aligned segments for each linkage group ranged from 187 (LG1) to 22 (LG19). A 1:1 relationship was detected on at least 21 LGs (77.7\%), excluding six LGs (LG1, LG8, LG14, LG19, LG26 and LG27) that obtained few percentages of mapped markers in a unique chromosome (equal to or less than $50 \%$ of the pacu segments). LG11 obtained the largest synteny relationship (83\% of SNPs) to a unique chromosome (Am24), followed by LG23 to the chromosome Am20 (82.5\% of SNPs). However, LG1 showed synteny to two chromosomes (Am7 and Am8), whereas three LGs (LG14, LG15 and LG16) were merged to a unique chromosome
(Am3). Additionally, genomic synteny was not conclusive for two LGs (LG19 and LG27), showing a poor synteny relationship with any chromosome of the blind cave tetra species (Fig. 3).

\section{Genome wide association analysis (GWAS)}

In total, 22 suggestive QTLs presenting association (AGV $>1 \%$ ) with $A$. hydrophila resistance were detected in 17 linkage groups, of which 5 were only associated with TS (LGs 12,13b, 19, 23 and 27), 3 only associated with TD (5b, 6 and 10b), and 14 were registered in association for both traits $(1,2,3,4 a, 4 b, 5 a, 7 a, 7 b, 9,10 a$, 11, 13a, 17 and 18) (Table 2, Figs. 4 and 5). Additionally, 38 immune system genes were located close to the identified QTLs (Table 2).

\section{Discussion}

Studies on selection of superior genotypes related to resistance have been reported in several aquaculture species $[13,25,26]$, however, no prior studies have focused on species produced in the Neotropical region. The major contribution of this study was to generate and apply genomic tools to improve the understanding of the genomic architecture of resistance against A. hydrophila in pacu, as a key step to harness genomic information to improve selection processes directed to disease resistance in this Neotropical fish species. Recently, dense SNP arrays have facilitated researchers assessing the association between genome-wide markers and utilizing them for optimization of the disease resistance through genetic improvement in aquaculture [21, 27-29]. However, whereas considerable investment for the 


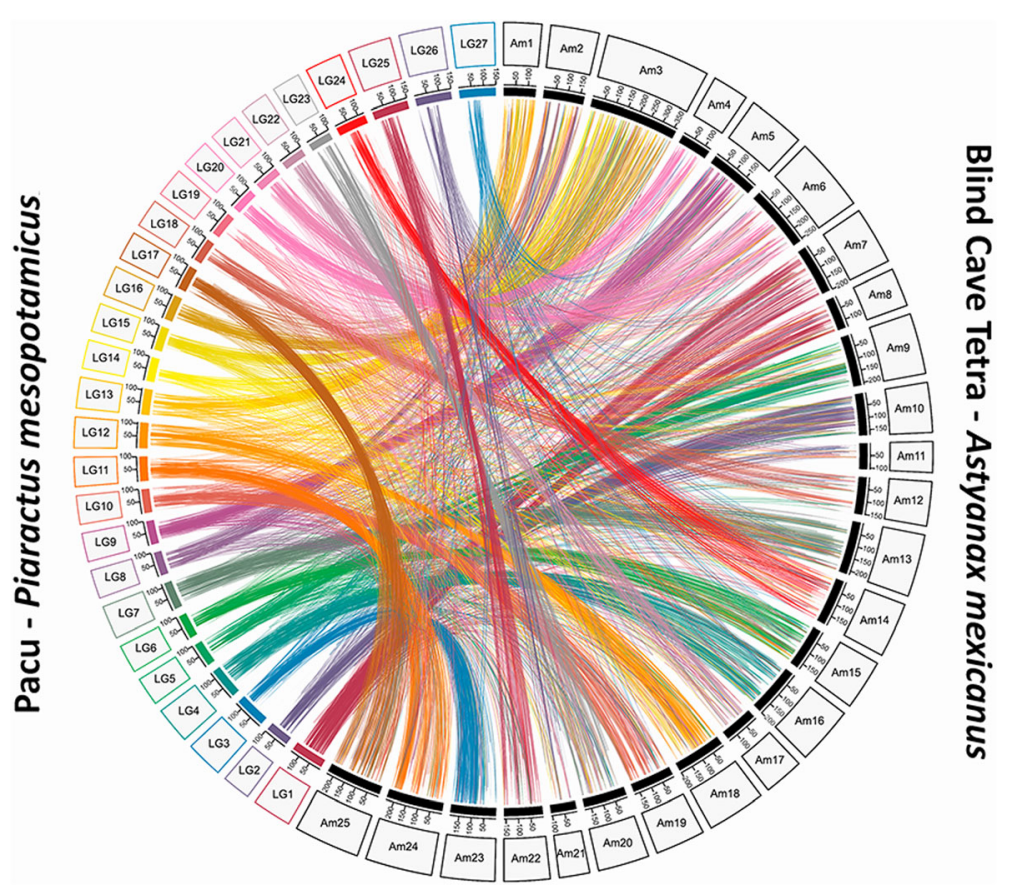

Fig. 3 Genomic synteny showed by Circos diagram for each pair of alignments between the linkage groups of pacu (Piaractus mesopotamicus) $(\mathrm{LG})$ and the chromosomes of blind cave tetra species (Astyanax mexicanus) (Am)

development and application of dense SNP arrays are required, techniques such as RAD-Seq require fewer resources, especially when directed for smaller scale programs, offering a viable alternative to identify and apply SNP datasets for breeding program studies [30]. Recent studies have demonstrated that RAD-Seq allowed the identification of some QTLs associated with bacterial cold-water disease in rainbow trout [31], as well as to resistance to viral nervous necrosis in European sea bass [24].

\section{Genetic parameters}

The results of genetic parameters revealed significant genetic variation for $A$. hydrophila resistance, with moderate heritability values (both to pedigree and genomicbased data). The heritability estimates were higher than those previously performed in different pacu populations $\left(h^{2}=0.15\right.$ for TS and $h^{2}=0.12$ for TD) [6]. In general, our results were within the reference range of heritability previously reported for $A$. hydrophila resistance in other species, such as Clarias macrocephalus, Megalobrama amblycephala, and Labeo rohita, ranging from 0.12 to 0.39 [32-34]. Nevertheless, lower values have also been found for A. hydrophila resistance in rohu carp (Labeo rohita) and common carp (Cyprinus carpio), with values of 0.02 and 0.04 , respectively [32, 35]. Therefore, the heritability values achieved for both resistance traits suggest that they will respond satisfactorily to genetic selection.

\section{Linkage map and synteny analysis}

In this study, we report genome-scale SNP discovery and medium-density genetic map construction in pacu. These genomic tools enable analysis of productive traits (e.g., disease resistance) by performing GWAS analysis and providing insights on the genetic architecture of these production traits, as proposed in this study approaching the resistance to $A$. hydrophila in pacu. The linkage map was comprised of 27 linkage groups that correspond to the number of chromosomes of pacu, arranging 10,220 loci (Fig. 2). In terms of Neotropical fish species, the only available linkage map was constructed for tambaqui Colossoma macropomum [36], a species from the same group (Serrasalmidae family). Our results were structurally similar to the linkage map constructed for tambaqui (C. macropomum), which used the information of 7734 SNPs to obtain a map length of 2811 $\mathrm{cM}$, with an average marker interval of $0.39 \mathrm{cM}$. Here, we prefer to use the genome of the blind cave tetra $(A$. mexicanus) as the reference genome to perform the synteny analysis instead of zebrafish, because the former is more related to pacu than the latter, which resulted in considerable homology between the LGs of pacu and chromosomes of $A$. mexicanus. A conserved synteny on the majority of LGs was identified between pacu and $A$. mexicanus genomes (Fig. 3), and a weak syntenic relationship was found in only 6 LGs. Therefore, although the reference genome of pacu is still not available, the resulting linkage map with conserved synteny to the 
Table 2 SNP markers associated with test survival (TS) and time of death (TD) traits estimated on pacu against Aeromonas hydrophila infection, using GBLUP and wGBLUP methods

\begin{tabular}{|c|c|c|c|c|}
\hline \multirow[t]{2}{*}{ QTL } & \multirow{2}{*}{$\begin{array}{l}\text { GWAS } \\
\text { method }\end{array}$} & \multicolumn{2}{|c|}{ AGV (\%) } & \multirow{2}{*}{$\begin{array}{l}\text { Genes related } \\
\text { to the immune } \\
\text { system }\end{array}$} \\
\hline & & TS & TD & \\
\hline 1 & wGBLUP & 2.59 & 2.99 & anp32b, srebf2 \\
\hline 2 & wGBLUP & 4.05 & 1.89 & $a c b d 5$, rala, zkscan 1 \\
\hline 3 & wGBLUP & 1.17 & 1.31 & Irrc3b, myo16 \\
\hline $4 a$ & wGBLUP & 3.52 & 1.32 & camlg, tcf7, nlrc3 \\
\hline \multirow[t]{2}{*}{$4 b$} & GBLUP & - & 1.59 & tnfsf13b \\
\hline & wGBLUP & 1.65 & 5.34 & \\
\hline $5 a$ & wGBLUP & 1.19 & 1.40 & axl, emilin1 \\
\hline \multirow[t]{2}{*}{$5 b$} & GBLUP & - & 1.28 & kalrn, il4i1 \\
\hline & wGBLUP & - & 2.98 & \\
\hline 6 & wGBLUP & - & 3.96 & $\lg r 6$ \\
\hline \multirow[t]{2}{*}{$7 a$} & GBLUP & 1.13 & 1.07 & cyp27c1, fundcl \\
\hline & wGBLUP & - & 1.58 & \\
\hline $7 b$ & wGBLUP & 3.45 & 3.63 & inhbb, srcin 1, tcaf1 \\
\hline \multirow[t]{2}{*}{9} & GBLUP & 1.03 & - & tbk1, trim16, zmat3 \\
\hline & wGBLUP & 1.67 & 1.62 & \\
\hline $10 a$ & wGBLUP & 1.56 & 1.57 & mtmr10 \\
\hline $10 \mathrm{~b}$ & wGBLUP & - & 1.42 & - \\
\hline \multirow[t]{2}{*}{11} & GBLUP & 1.10 & 1.05 & rps6ka5, ccr3, cyp2k1 \\
\hline & wGBLUP & 1.19 & - & \\
\hline 12 & wGBLUP & 1.14 & - & - \\
\hline $13 a$ & wGBLUP & 1.18 & 2.74 & itpk1, mark4 \\
\hline $13 b$ & wGBLUP & 1.95 & - & myo18a, caln1 \\
\hline 17 & wGBLUP & 1.08 & 1.34 & tiam1 \\
\hline \multirow[t]{2}{*}{18} & GBLUP & - & 1.30 & lyz2, il12rb2 \\
\hline & wGBLUP & 1.16 & 15.65 & \\
\hline 19 & wGBLUP & 1.58 & - & unc $5 b$, znf3 \\
\hline 23 & wGBLUP & 2.06 & - & $s / k$ \\
\hline 27 & wGBLUP & 1.22 & - & - \\
\hline
\end{tabular}

genome of A. mexicanus will offer a framework for mapping candidate genes responsible for productive traits to be included in breeding programs of pacu.

\section{Genome wide association analysis (GWAS)}

In total, 22 suggestive QTLs associated to resistance against A. hydrophila (AGV > 1\%) were observed in 17 linkage groups (Figs. 4 and 5). This pattern of polygenic architecture was similarly found in other fish species challenged for A. hydrophila resistance [20] and for other bacterial diseases [25, 37].

Marker-assisted selection has been suggested as a viable approach for catfish breeding due to the limited number of QTLs involved in A. hydrophila resistance (3 QTLs presented in 3 linkage groups)
[21]. However, the absence of large effect QTLs suggests that marker-assisted selection cannot be considered an effective strategy to genetically improve resistance against $A$. hydrophila in the analyzed population of pacu, similarly to a previous QTL mapping study that associated 21 QTLs to 10 linkage groups for $A$. hydrophila resistance in rohu carp [20]. Therefore, the application of genomic selection [38] could be tested for selection accuracy of breeding values compared to traditional pedigree-based selection, and it can be used as an alternative to increase the selection response for disease resistance in pacu, as similarly performed for resistance of salmonid species [11, 13, 19, 28, 39].

Among the QTLs with highest AGV, six were identified adopting both models GBLUP and wGBLUP (4b, 5b, 7a, 9, 11 and 18) (Figs. 4 and 5). These six suggestive QTLs were located close to important candidate genes related to immune response, which may probably be involved in resistance against A. hydrophila infection (Table 2). Some of these genes were already reported in several studies involving the functioning of immune system mechanisms of fish in face of bacterial infections [40], corroborating the results of the present study and suggesting similar mechanisms for bacterial resistance in different fish species. As example, TANK-binding kinase 1-binding protein 1 ( $t b k 1$ ) gene had an essential role in the activation of pattern-recognition receptors, starting the innate immune responses against pathogens [41]. Tripartite motif-containing protein 16 (trim16) gene is a part of tripartite motif family which has also been associated with QTL regions for A. hydrophila resistance in the hybrid catfish [21]. Several studies have showed the involvement of this family of genes with signaling pathways for activation of murine macrophages [21], autophagic response [42], and interleukin secretion [43]. Interleukin 12 Receptor Subunit Beta2 (Il12rb2) is responsible in regulation of receptors to interleukin12 , a proinflammatory cytokine produced by phagocytic cells already identified in response to $A$. hydrophila infection [44]. Additionally, this gene is involved in the proliferation of T-cells as well as NK cells, enhancing the cytotoxic activity against the bacteria [45]. Lysozyme C-2 precursor (lyz2) is another gene responsible to contribute to the inflammatory response, as it is associated to activity of immune modulating agents and digestive function against gram-negative bacteria [46]. This gene has already been found in several fish species, such as salmonids, japanese flounder and upregulated in grass carp challenged with $A$. hydrophila [40, 47]. Therefore, further studies are needed on validation 
a

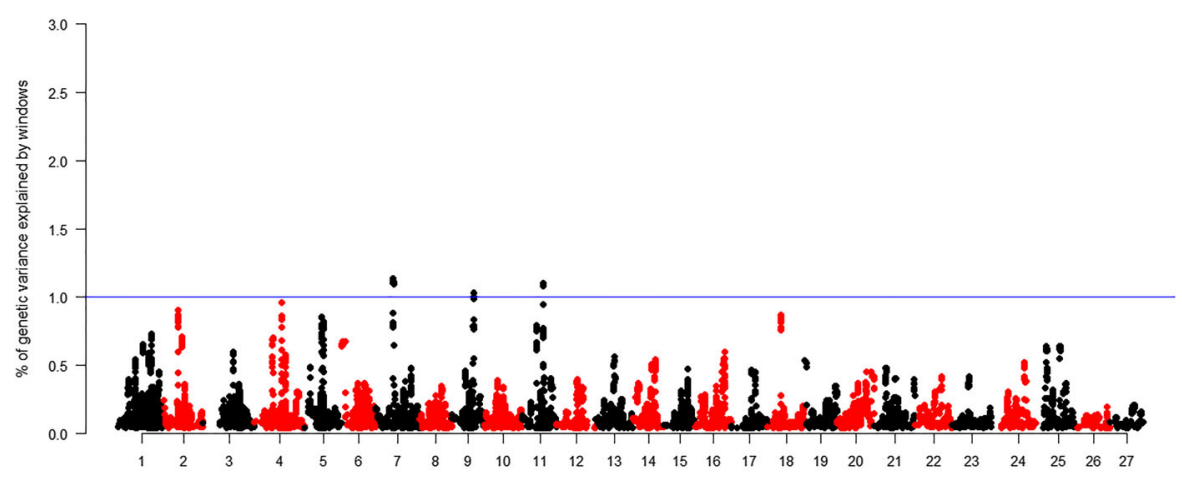

b

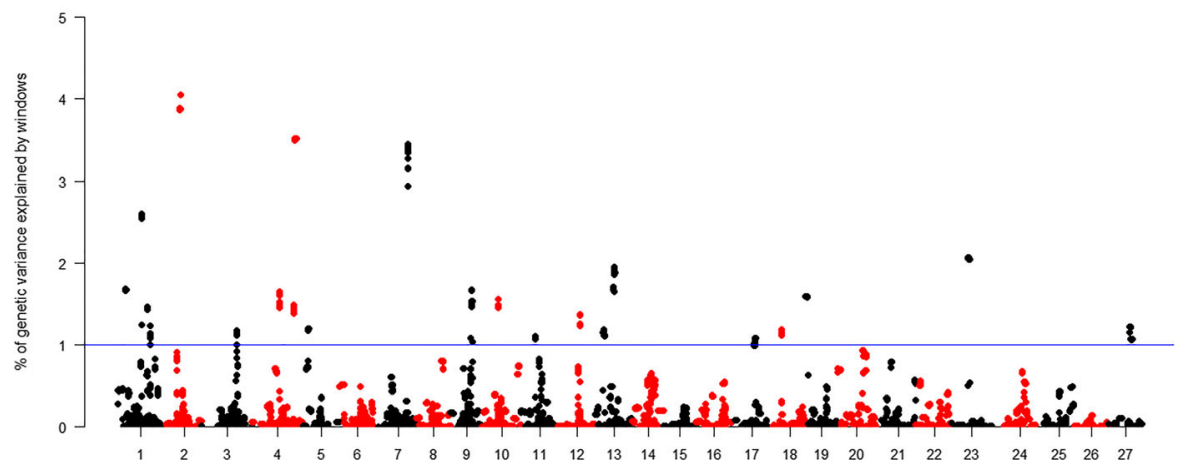

Fig. 4 Genomic association analysis (GWAS) for test survival (TS) against A. hydrophila infection in 14 pacu families by GBLUP (a) and wGBLUP (b) models

of these predicted genes as important components in the role of the genetic variation for resistance against $A$. hydrophila.

\section{Conclusion}

There have been several studies aiming to improve disease resistance via analysis of high-density SNP genotypes in aquaculture $[13,25,26]$, but until the present date, no studies have focused on species produced in the Neotropical region. The present study generated thousands of SNPs for pacu, which were used to identify the genetic architecture of $A$. hydrophila resistance through GWAS analyses, highlighting the effectiveness of genotyping-by-sequencing techniques for genomic analysis in non-model fish species. Our results suggest that this trait is under polygenic control in pacu. Thus, genomic selection might be suitable to incorporate molecular information to aim for the improvement of resistance to one of the most problematic diseases that affects the South American aquaculture.

\section{Methods}

\section{Origin of pacu families}

Genomic data were obtained from 381 juvenile individuals (6 months post hatch) belonging to 14 full-sibling families of pacu. The induced reproduction was generated in 2016 by a hierarchical mating scheme using 4 dams and 14 sires (approximately 1 dam for each 4 sires). These breeders were originated from three different fish farms located at Sao Paulo State (Brazil). The names of the fish farms were kept confidential. Induced spawning was successfully carried out injecting carp pituitary extract, similarly to Mastrochirico-Filho et al. [6].

After incubation of fish embryos and hatching process, artemia were offered to the larvae during 20 days in 201 conical fiberglass incubators installed in the Laboratory of Genetics in Aquaculture and Conservation (LaGeAC), at the São Paulo State University (UNESP), Jaboticabal city (São Paulo State, Brazil). Posteriorly, fish food with $50 \%$ of crude protein were gradually incorporated into the diet. In the fingerling stage, $1.2 \mathrm{~mm}$ pelleted feeds were used (40\% of crude protein), being gradually replaced by 2 to $3 \mathrm{~mm}$ pelleted feeds (36\% of crude protein) provided twice daily in 601 tanks. Passive integrated transponder (PIT) tags were inserted into the intraperitoneum of individuals when they reached at least $5 \mathrm{~g}$ to maintain the pedigree information during the challenge experiments. Laterally, fish were kept in 8001 fiberglass tanks up to about 6 months post hatch. 

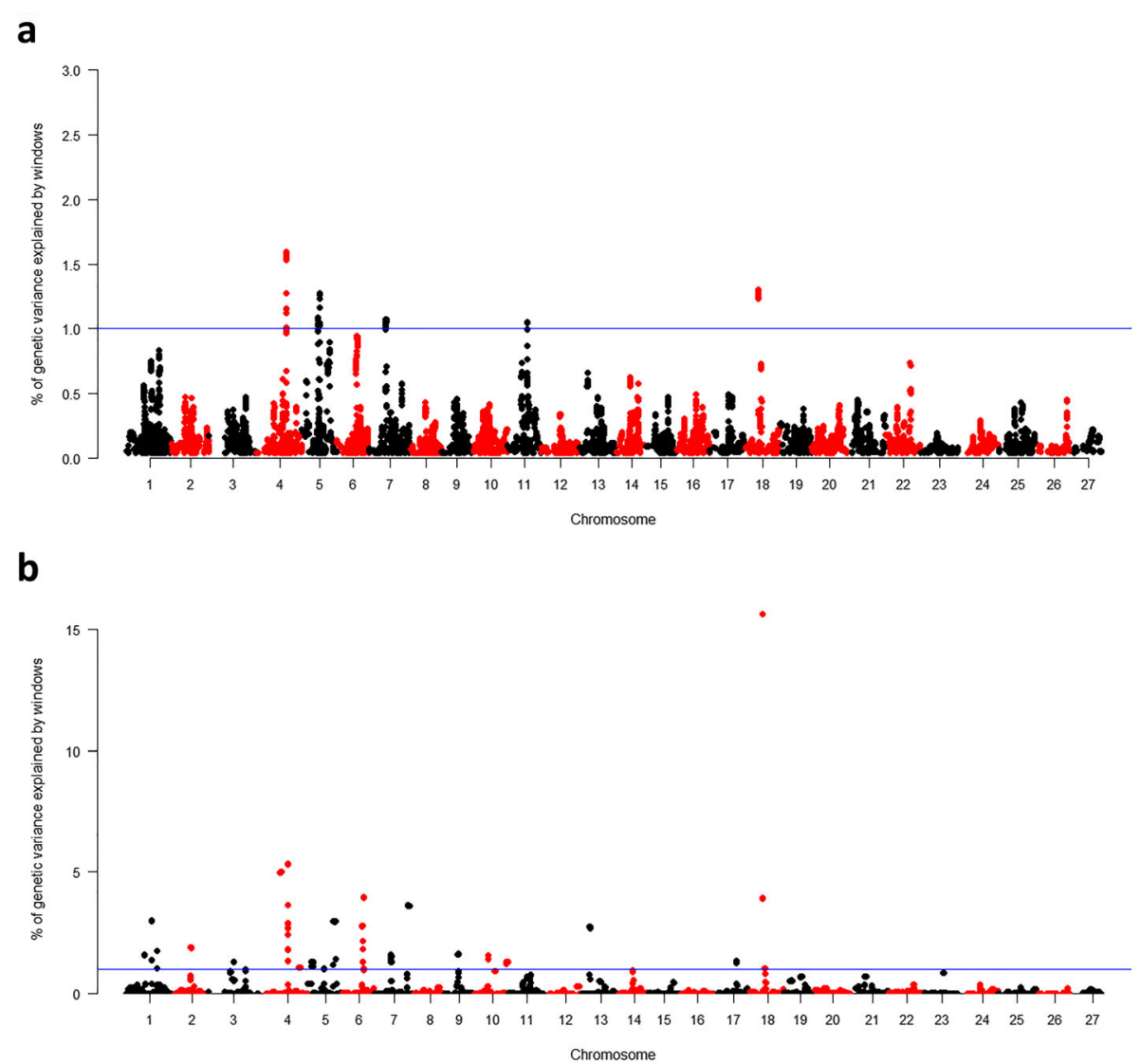

Fig. 5 Genomic association analysis (GWAS) for time of death (TD) against A. hydrophila infection in 14 pacu families by GBLUP (a) and wGBLUP (b) models

\section{Aeromonas hydrophila challenge}

The protocols for the Aeromonas hydrophila challenge, including the bacteria strain preparation, were similar to Mastrochirico-Filho et al. [6]. Briefly, a lethal dose in $50 \%$ of the individuals (LD50) was tested in 60 randomly selected fish from the same pacu families. Prior to the challenge, subsamples of populations were checked by microbiological tests to detect the presence of $A$. hydrophila and other pathogenic bacteria. In relation to the challenge test design, 381 juvenile individuals were distributed among three communal tanks (length $=2 \mathrm{~m}$, width $=1 \mathrm{~m}$, depth $=1$ $\mathrm{m})$, where approximately 10 individuals from each family (9.1, SD 1.3 individuals) were randomly distributed into each treatment tank (about 127 fish per tank), according to the sample size recommendation for disease resistance challenges proposed by Gjedrem and Baranski [48].

Before the bacteria inoculation, fish were placed for $1 \mathrm{~min}$ in a 31 plastic washbasin containing benzocaine dissolved in water $(10 \mathrm{mg} / \mathrm{l})$, with continuous aeration, and weighed. The mean weight of the individuals prior to the bacteria inoculation time was $23.0 \mathrm{~g}$ (SD
$9.06 \mathrm{~g})$. When the individuals reached the dormant state, intraperitoneal inoculation of the predefined $\mathrm{LD}_{50}$ of $A$. hydrophila $\left(8 \times 10^{5} \mathrm{CFU} / \mathrm{g}\right.$ body weight $)$ were injected, according to protocols carried out by Mastrochirico-Filho et al. [6]. In parallel, 10 fish from each family (140 fish) were also used as control and kept in a separate but similar tank conditions (called as control tank). Individuals of the control tank were injected by intraperitoneal inoculation of phosphatebuffered-saline solution (PBS). An independent water recirculation system was maintained for both treatment and control tanks, similarly to MastrochiricoFilho et al. [6].

Fish mortality events were registered all the time in the initial 3 days, and in 8 -h intervals in the remaining days of the challenge experiment. Susceptible fish with clinical signs of $A$. hydrophila infection (e.g. disequilibrium, hemorrhage, isolation from the group) were recorded and removed immediately from the tanks. A subsample of dead fish was necropsied and suffered routine microbiological tests to confirm mortality by $A$. hydrophila and discard a possibility of infection caused by other pathogens. 
At the end of the challenge period, surviving fish were checked externally for detection of clinical signs of the disease, and posteriorly euthanized using benzocaine.

\section{Genetic parameter estimation}

Resistance was assessed as survival to the challenge test using the trait definitions of Mastrochirico et al. [6], such as Test survival (TS), which was analysed using a binary threshold (probit) model (THR) to account for the binary nature of the trait; and Time of death (TD), which was scored in hours (if fish survived to the end of challenge period, the time was recorded as $64.6 \mathrm{~h}$ ) and it was analysed using a linear mixed model (LIN). The univariate animal models were defined as:

$$
y_{i j}=\mu+t_{i}+w_{i j}+a_{i j}+e_{i j}(\mathrm{LIN})
$$

where, $y_{i j}$ was the phenotype for the fish $j$, in tank $i ; \mu$ was the fixed effect of the overall mean; $t_{i}$ was the fixed effect of the tank $i$; $w_{i j}$ was the covariate of weight prior bacteria inoculation for fish $j$, in tank $i$; $a_{i j}$ was the random animal genetic effect of individual $j$, in tank $i$; and $e_{i j}$ was the random residual effect for the fish $j$, in tank $i$.

$$
\operatorname{Pr}\left(y_{i j}\right)=\Phi\left(\mu+t_{i}+w_{i j}+a_{i j}\right)(\mathrm{THR})
$$

where, $y_{i j}$ was the phenotype (TS) for the fish $j$, in the tank $i$; $\Phi(\cdot)$ was the cumulative standard normal distribution and the other parameters were similar to those described above.

THR and LIN models were fitted to estimate variance components by ASREML 3.0 package [49]. For all the models, the random animal genetic effect was assumed to be $N\left(0, A \sigma_{a}^{2}\right)$, where $A$ was the pedigree-based additive genetic kinship matrix among all the animals included in the population and $\sigma_{a}^{2}$ was the additive genetic variance. Random residuals for LIN were assumed to be $N\left(0, I \sigma_{e}^{2}\right)$, where I was an identity matrix and $\sigma_{e}^{2}$ was the residual variance. For THR model, the residual variance on the underlying scale was set to 1 . For both models, heritability was calculated as:

$$
h^{2}=\frac{\sigma_{a}^{2}}{\sigma_{a}^{2}+\sigma_{e}^{2}}
$$

Where, $\sigma_{a}^{2}$ was the additive genetic variance and $\sigma_{e}^{2}$ was the residual variance.

\section{DNA extraction and construction of RAD libraries}

For RAD-Seq analysis, fins from 391 individuals (373 offspring +18 parents) were sampled for DNA extraction using the Dneasy Blood \& Tissue QIAGEN kit. The quantification of extracted DNA ( $\mathrm{ng} / \mu \mathrm{l})$ was measured by the Qubit fluorescence detector using the Qubit dsDNA BR Assay kit (Invitrogen, USA).

Each library was constructed with approximately 29 individuals identified with barcodes (14 libraries in total). Genomic DNA from each individual was digested by $S b f l$ enzyme. For each $11.35 \mu \mathrm{l}$ of DNA (concentration at 10 $\mathrm{ng} / \mu \mathrm{l}$ ), $0.25 \mu \mathrm{l}$ of $S b f l$ and $1.3 \mu \mathrm{l}$ of NEBuffer 4 (New England Biolabs) were used. The enzyme digestion was performed at $37^{\circ} \mathrm{C}$ for $1 \mathrm{~h}$, followed by an inactivation period of $20 \mathrm{~min}$ at $80^{\circ} \mathrm{C}$.

Barcode adapters were ligated to the end of the DNA fragments following digestion with Sbfl, using the T4 DNA ligase (New England Biolabs). The ligation was incubated at $20^{\circ} \mathrm{C}$ for $2 \mathrm{~h}$, and then at $65^{\circ} \mathrm{C}$ for $20 \mathrm{~min}$. Following library construction, their quality was determined by PCR that combined $8.5 \mu \mathrm{l}$ of water; $12.5 \mu \mathrm{l}$ Phusion High-Fidelity Master Mix; $1 \mu \mathrm{l}$ of RAD primer mix (forward and reverse) and $1 \mu \mathrm{l}$ of digested DNA. The amplification was carried out with 18 cycles in a thermocycler $\left(98^{\circ} \mathrm{C}\right.$ for $10 \mathrm{~s}, 65^{\circ} \mathrm{C}$ for $30 \mathrm{~s}, 72^{\circ} \mathrm{C}$ for 30 s) and $72{ }^{\circ} \mathrm{C}$ for $5 \mathrm{~min}$. Size selection (300-500 bp) was carried out using excision of the appropriate band from gel electrophoresis. Purification was then carried out by the MinElute Gel Extraction kit, following the recommendations of the manufacturer. The concentration of each library was then normalized to $2.5 \mathrm{~nm}$ for sequencing by Edinburgh Genomics (University of Edinburgh, UK) on Illumina NovaSeq 6000 platform (flow cell Type $\mathrm{S} 1$ in 1 lane).

\section{Identification of SNPs from RAD-Seq technology}

RAD sequences were filtered to discard those of low quality and posteriorly trimmed to $150 \mathrm{bp}$. Stacks 2.0 software [50] eliminated the ambiguous barcode sequences from the subsequent process. The remaining sequences were then separated according to the barcodes linked to the reads. Identical sequences based on similarity were filtered off using Dedupe Python Library [51] maintaining a single representative sequence. In relation of the main parameters that control locus formation by Stacks 2.0 software [50], the minimum depth of coverage $(\mathrm{m})$ to create a putative allele (stack) was 3 . The number of mismatches allowed between two alleles of sample (parameter M) was 3. Considering the RAD locus cata$\log$ containing parental individuals, the number of mismatches allowed between two alleles from the population to form a catalog was 3 . Only loci present in at least $70 \%$ of individuals were considered to identify putative SNPs (call rate $>0.70$ ). In order to differentiate putative SNPs from sequencing errors, Plink 1.9 software [52] was used to exclude SNPs with minor allele frequencies (MAF) lower than $0.05, p$-value of HardyWeinberg disequilibrium (PHWE) lower than $1 \times 10^{-6}$. Additionally, SNPs with more than $20 \%$ of genotyping 
error rate (geno 0.2 ) and more than $10 \%$ of Mendelian error rate were also discarded. In relation to filter out individuals, samples presenting more than $30 \%$ of missing genotypes (mind 0.3) were excluded for linkage map construction.

\section{Linkage map and synteny analysis}

Analysis of parentage assignment was performed by software Cervus3 [53, 54] using sex information of parents to confirm the pedigree. A linkage map was created using the modules of Lep-MAP 3 software [55]. ParentCall2 confirmed reliable parental genotypes using joint information on offspring and parents. Filtering2 was used to remove markers with significant segregation distortion (dataTolerance = 0.001). Markers were assigned into 27 linkage groups (LGs) (corresponding to the 27 pairs of chromosomes in pacu) by SeparateChromosomes2. In the LG assignment, an optimized LOD score of 8.6 was achieved binning the markers into LGs by adoption of LOD scores ranging from 4 to 15 [56]. The orphan markers were assigned to existing linkage groups (optimized LOD score $=6.7$ ) using JoinSingles 2 to maximize the map-abilities of the total input of markers, and ordered the binned markers within linkage groups using OrderMarkers2. The generated linkage map was drawn using the LinkageMapView [57]. In order to verify the ordering of loci within the LGs belonging to the linkage map, correspondence synteny analysis between the chromosomes of blind cave tetra (Astyanax mexicanus) and the LGs for pacu was performed adopting the circos plots by Circa software (http://omgenomics.com/circa/).

\section{Genome-wide association study (GWAS)}

GWAS for TS and TD traits were performed by genomic BLUP (GBLUP) and weighted genomic BLUP (wGBLUP) methods, adopting windows of 20 adjacent SNPs, and analyzed by BLUPF90 family of programs [58]. All available information on genotyped fish, including pedigree and phenotype records ( $n=332$ individuals) was considered. The animal models applied to the test was the same used for estimation of genetic parameters (above), but with addition of the genotype data. TD was analyzed as a linear trait using BLUPF90, whereas TS was analyzed as a threshold trait using THRGIBBS1F90. Gibbs sampling scheme was run considering one million iterations, of which the first 200,000 iterations were discarded. From the remaining 800,000 iterations one sample was saved from every 100 iterations.

The SNP based variance components and genomic estimated breeding values (GEBVs) were estimated, where $\alpha$ were a vector of random additive genetic effects with distribution $\sim N\left(0, G \sigma_{a}^{2}\right)$ and the numerator matrix $A$ was replaced by a genomic relationship matrix $G$ [59], that was constructed as:

$$
G=Z D Z^{\prime} \lambda
$$

where, $Z$ was the incidence matrix relating genotypes of SNPs with phenotypes (TS or TD), $D$ was a diagonal inverse matrix with the expected variance for all SNPs, and $\lambda$ was a weighting vector derived from the observed SNP frequencies. For GBLUP, matrix $D$ equals identity matrix (I), while in wGBLUP, matrix $D$ was estimated using the SNP effects using PREGSF90 and POSTGSF90. For this, GEBV $\left(\widehat{a}_{g}\right)$ were converted to SNP effects and the weights of SNP effect were refined being 1 for the first iteration, which means that all SNPs had the same weight. For the next iteration (2nd iteration), the weights were SNP-specific variances that were calculated through the estimates of the SNP allele-substitution effect of the preceding iteration and the corresponding SNP allele frequencies [60]. The equation for predicting SNP effects $(\hat{u})$ was $[60,61]$ :

$$
\hat{u}=\lambda D Z \ddot{\mathbb{E}} G^{-1} \widehat{a_{g}}
$$

where, $\hat{u}$ represented the vector of SNP effects and $\widehat{a_{g}}$ the vector of GEBV of genotyped animals. With the results, the individual variance of SNP effects was estimated as [62]:

$$
d_{i(t+1)}=\hat{u}_{j(i)}^{2} 2 p_{j}\left(1-p_{j}\right)
$$

where, $\hat{u}_{j(i)}^{2}$ was considered the square of the $j$ th SNP marker effect in the $i$ th individual, and $p_{j}$ expressed the observed allele frequency for the second allele of the $j$ th marker. After normalizing the matrix $D$ and the weights of SNPs such that the total genetic variance remains constant, the percentage of additive genetic variance explained by each SNP window could be estimated as following:

$$
\frac{\operatorname{Var}\left(u_{i}\right)}{\sigma_{a}^{2}} \times 100 \%=\frac{\operatorname{Var}\left(\sum_{i}^{20} Z_{i} \widehat{a_{g_{i}}}\right)}{\sigma_{a}^{2}} \times 100 \%
$$

In total, 12,657 SNPs and 268 genotyped animals which passed on the quality control (call rate $>90 \%$; MAF $>0.05$ ) were analyzed. Manhattan plots based on the percentage of genetic variance explained by the $i$ th SNP window was plotted by R-qqman [63] using $R$ software.

SNP windows that explained more than $1 \%$ of the AGV for the traits were defined as suggestive QTL associated with A. hydrophila resistance [19, 64]. RAD-tag containing the highly associated SNPs were aligned against the Pygocentrus nattereri genome (a 
phylogenetically close fish species) using Nucleotide Basic Local Alignment Search Tool (BLASTn) to evaluate the presence of putative genes associated with the trait between the first and the last position of each 20 SNP window. The putative candidate genes identified were within or adjacent to each associated SNP.

\section{Abbreviations}

A. hydrophila: Aeromonas hydrophila; AGV: Additive Genetic Variance; Am: Astyanax mexicanus chromosome; BLASTn: (nucleotide) Basic Local Alignment Search Tool; bp: Base pairs; CFU/g: Colony Forming Unit per gram; cM: Centimorgan; e.g.: Exempli gratia; g: Grams; GEBV: Genomic estimated breeding values; GWAS: Genome-Wide Association Study; h: Hours; Kb: Kilobases; I: Liters; LD50: Lethal dose in 50\% of individuals; LG: Linkage Group; LIN: Linear model; m: Meter; $\mathrm{m}^{3}$ : Cubic meter; MAF: Minor Allele Frequency; mg/kg: Milligram per kilogram; mg/l: Milligram per liter; min: Minutes; mm: Millimeters; ng/ul: Nanogram per microliter; nm: Nanometers; P. mesopotamicus: Piaractus mesopotamicus; QTLs: Quantitative Trait Loci; RAD-Seq: Restriction Site Associated DNA Sequencing; s: Seconds; SD: Standard Deviation; SNPs: Single Nucleotide Polymorphisms; GBLUP: Genomic Best Linear Unbiased Prediction; TD: Time of Death; THR: Threshold (probit) model; TS: Test Survival; w: Watt; wGBLUP: Weighted Genomic Best Linear Unbiased Prediction; $\mu l$ : Microliter

\section{Acknowledgements}

We thanks to The Roslin Institute (College of Medicine and Veterinary Medicine, University of Edinburgh), where the laboratorial infrastructure supported the preparation of the RAD-Seq libraries.

\section{Authors' contributions}

Conceived and designed the experiments: VAMF and DTH. Performed the experiments: VAMF, MVF, RBA and FP. Analysed the data: VAMF, CHSB, RU, RC, APG, CP, JMY, RDH and DTH. Contributed reagents and materials: FP, $\mathrm{RDH}$ and DTH. Manuscript preparation: VAMF, RC, APG, CP, JMY, RDH and DTH. All authors read the article and approved the final version.

\section{Funding}

This work was supported by São Paulo Research Foundation (FAPESP grant 2016/21011-9, 2016/18294-9, 2017/26900-9 and 2018/08416-5) providing a PhD fellowship for VAMF and funds for the sequencing service; Comisión Nacional de Investigación Científica y Tecnológica (International Call FAPESPCONICYT) providing funds for the experiment costs; National Council for Scientific and Technological Development (CNPq grant 311559/2018-2 and 140740/2016-3) providing a PhD scholarship and financing for the study design; and Coordenação de Aperfeiçoamento de Pessoal de Nível Superior - Brasil (CAPES - Finance Code 001 and CAPES/PRINT) providing funds for project costs.

\section{Availability of data and materials}

RAD sequencing raw reads supporting the conclusions of this manuscript have been deposited in the NCBI Sequence Read Archive (SRA) database "RAD-Seq of pacu challenged with Aeromonas hydrophila" (SRX8380423), under the accession number PRJNA634462 (https://www.ncbi.nlm.nih.gov/ sra/?term=PRJNA634462). All scripts are available upon request to the corresponding author

Furthermore, the representative genome of blind cave tetra species (Astyanax mexicanus) used in genomic synteny analysis was obtained from the NCBI database (https://www.ncbi.nlm.nih.gov/genome/13073), under the accession number PRJNA237016.

\section{Ethics approval and consent to participate}

This study was conducted in strict accordance with the recommendations of the National Council for Control of Animal Experimentation (CONCEA) (Brazilian Ministry for Science, Technology and Innovation) and was approved by the Ethics Committee on Animal Use (CEUA number 19.005/17) of Faculdade de Ciências Agrárias e Veterinárias, UNESP, Campus Jaboticabal, SP, Brazil. A formal written consent to participate of this study was obtained from the farm owners, who provided the breeders to create the families.

\section{Consent for publication}

Not applicable.

\section{Competing interests}

The authors declare that they have no competing interests.

\section{Author details}

${ }^{1}$ São Paulo State University (Unesp), Aquaculture Center of Unesp, Via de Acesso Prof. Paulo Donato Castellane, s/n, Jaboticabal, SP 14884-900, Brazil. ${ }^{2}$ Universidade Federal Rural do Rio de Janeiro, Seropédica, RJ 23897-000, Brazil. ${ }^{3}$ São Paulo State University (Unesp), School of Agricultural and Veterinarian Sciences, Jaboticabal, SP, Brazil. ${ }^{4}$ National Council for Scientific and Technological Development (CNPq), Brasília, DF 71605-001, Brazil. ${ }^{5}$ The Roslin Institute and Royal (Dick) School of Veterinary Studies, The University of Edinburgh, Midlothian EH25 9RG, UK. ${ }^{6}$ Facultad de Ciencias Veterinarias y Pecuarias, Universidad de Chile, Santiago, Chile.

Received: 1 May 2020 Accepted: 21 September 2020

Published online: 29 September 2020

\section{References}

1. Subasinghe RP, Bondad-Reantazo MG, McGladdery SE. Aquaculture development, health and wealth. In: Subasinghe RP, Bueno P, Phillips MJ, Hough C, McGladdery SE, Arthur JR, editors. Aquaculture in the Third Millennium. Technical Proceedings of the Conference on Aquaculture in the Third Millennium. Bangkok: Naca and FAO; 2001. p. 167-91.

2. Huang $K$, Nitin N. Edible bacteriophage based antimicrobial coating on fish feed for enhanced treatment of bacterial infections in aquaculture industry. Aquaculture. 2019. https://doi.org/10.1016/j.aquaculture.2018.12.026.

3. Zhang D, Xu D, Shoemaker C. Experimental induction of motile Aeromonas septicemia in channel catfish (Ictalurus punctatus) by waterborne challenge with virulent Aeromonas hydrophila. Aquacult Rep. 2016. https://doi.org/10. 1016/j.aqrep.2015.11.003.

4. Farias THV, Levy-pereira N, Alves LO, Dias DC, Tachibana L, Pilarski F, Belo MAA, Ranzani-paiva MJT. Probiotic feeding improves the immunity of pacus, Piaractus mesopotamicus, during Aeromonas hydrophila infection. Anim Feed Sci Tech. 2016. https://doi.org/10.1016/j.anifeedsci.2015.11.004.

5. IBGE. Produção da pecuária municipal v. 44. Rio de Janeiro: IBGE; 2016.

6. Mastrochirico-Filho VA, Ariede RB, Freitas MV, Lira LVG, Agudelo JFG, Pilarski F, Neto RVR, Yáñez JM, Hashimoto DT. Genetic parameters for resistance to Aeromonas hydrophila in the Neotropical fish pacu (Piaractus mesopotamicus). Aquaculture. 2019. https://doi.org/10.1016/j.aquaculture. 2019.734442.

7. Jia Z, Chen L, Ge Y, Li S, Peng W, Li C, Zhang Y, Hu X, Zhou Z, Shi L, Xu P. Genetic mapping of koi herpesvirus resistance (KHVR) in Mirror carp (Cyprinus carpio) revealed genes and molecular mechanisms of disease resistance. Aquaculture. 2020. https://doi.org/10.1016/j.aquaculture.2019. 734850.

8. Palaiokostas C, Vesely T, Kocour M, Prchal M, Pokorova D, Piackova V, Pojezdal L, Houston RD. Optimizing genomic prediction of host resistance to koi herpesvirus disease in carp. Front Genet. 2019. https://doi.org/10. 3389/fgene.2019.00543.

9. Tadmor-Levi R, Hulata G, David L. Multiple interacting QTLs affect disease challenge survival in common carp (Cyprinus carpio). Heredity. 2019. https:// doi.org/10.1038/s41437-019-0224-0.

10. El-Magd MA, El-Said KS, El-Semlawy AA, Tanekhy M, Afifi M, Mohamed TM. Association of $\mathrm{MHC} \| \mathrm{A}$ polymorphisms with disease resistance in Aeromonas hydrophila-challenged Nile tilapia. Dev Comp Immunol. 2019 https://doi.org/10.1016/j.dci.2019.03.002.

11. Bangera R, Correa K, Lhorente JP, Figueroa R, Yáñez JM. Genomic predictions can accelerate selection for resistance against Piscirickettsia salmonis in Atlantic salmon (Salmo salar). BMC Genomics. 2017. https://doi. org/10.1186/s12864-017-3487-y.

12. Robledo D, Matika O, Hamilton A, Houston RD. Genome-Wide association and genomic selection for resistance to Amoebic Gill disease in Atlantic Salmon. G3-Genes Genom Genet. 2018. https://doi.org/10.1534/g3.118. 200075

13. Yoshida GM, Bangera R, Carvalheiro R, Correa K, Figueroa R, Lhorente JP, Yáñez JM. Genomic prediction accuracy for resistance against Piscirickettsia salmonis in farmed rainbow trout. G3-Genes Genom Genet. 2018. https:// doi.org/10.1534/g3.117.300499. 
14. Sonesson AK, Meuwissen THE. Testing strategies for genomic selection in aquaculture breeding programs. Genet Sel Evol. 2009. https://doi.org/10. 1186/1297-9686-41-37.

15. Yáñez JM, Lhorente JP, Bassini LN, Oyarzún M, Neira R, Newman S. Genetic co-variation between resistance against both Caligus rogercresseyi and Piscirickettsia salmonis, and body weight in Atlantic salmon (Salmo salar). Aquaculture. 2014. https://doi.org/10.1016/j.aquaculture.2014.06.026.

16. Houston RD, Haley CS, Hamilton A, Guy DR, Tinch AE, Taggart JB, McAndrew BJ, Bishop SC. Major quantitative trait loci affect resistance to infectious pancreatic necrosis in Atlantic salmon (Salmo salar). Genetics. 2008. https://doi.org/10.1534/genetics.107.082974.

17. Moen T, Baranski M, Sonesson AK, Kjøglum S. Confirmation and fine-mapping of a major QTL for resistance to infectious pancreatic necrosis in Atlantic salmon (Salmo salar): population-level associations between markers and trait. BMC Genomics. 2009. https://doi.org/10.1186/1471-2164-10-368.

18. Yáñez JM, Houston RD, Newman S. Genetics and genomics of disease resistance in salmonid species. Front Genet. 2014. https://doi.org/10.3389/ fgene.2014.00415.

19. Barría A, Christensen KA, Yoshida GM, Correa K, Jedlicki A, Lhorente JP, Davidson WS, Yáñez JM. Genomic predictions and genome-wide association study of resistance against Piscirickettsia salmonis in coho salmon (Oncorhynchus kisutch) using ddRAD sequencing. G3-Genes Genom Genet. 2018. https://doi.org/10.1534/g3.118.200053.

20. Robinson N, Baranski M, Mahapatra KD, Saha JN, Das S, Mishra J, Das P, Kent M, Arnyasi M, Sahoo PK. A linkage map of transcribed single nucleotide polymorphisms in rohu (Labeo rohita) and QTL associated with resistance to Aeromonas hydrophila. BMC Genomics. 2014. https://doi.org/10.1186/14712164-15-541.

21. Wang W, Tan S, Luo J, Shi H, Zhou T, Yang Y, Jin Y, Wang X, Niu D, Yuan Z, Gao D, Dunham R, Liu Z. GWAS analysis indicated importance of NF-KB signaling pathway in host resistance against motile Aeromonas septicemia disease in catfish. Mar Biotechnol. 2019. https://doi.org/10.1007/s10126-01909883-0.

22. Baird NA, Etter PD, Atwood TS, Currey MC, Shiver AL, Lewis ZA, Selker EU, Cresko WA, Johnson EA. Rapid SNP discovery and genetic mapping using sequenced RAD markers. PLoS One. 2008. https://doi.org/10.1371/journal. pone.0003376

23. Davey JW, Cezard T, Fuentes-Utrilla P, Eland C, Gharbi K, Blaxter ML. Special features of RAD sequencing data: implications for genotyping. Mol Ecol. 2013. https://doi.org/10.1111/mec.12084.

24. Palaiokostas C, Cariou S, Bestin A, Bruant JS, Haffray P, Morin T, Cabon J, Allal F, Vandeputte M, Houston RD. Genome-wide association and genomic prediction of resistance to viral nervous necrosis in European sea bass (Dicentrarchus labrax) using RAD sequencing. Genet Sel Evol. 2018. https:// doi.org/10.1186/s12711-018-0401-2.

25. Palaiokostas C, Ferraresso S, Franch R, Houston RD, Bargelloni L. Genomic prediction of resistance to pasteurellosis in gilthead sea bream (Sparus aurata) using 2b-RAD sequencing. G3-Genes Genom Genet. 2016. https:// doi.org/10.1534/g3.116.035220

26. Vallejo RL, Leeds TD, Fragomeni BO, Gao G, Hernandez AG, Misztal I, Welch TJ, Wiens GD, Palti Y. Evaluation of genome-enabled selection for bacterial cold water disease resistance using progeny performance data in rainbow trout: insights on genotyping methods and genomic prediction models. Front Genet. 2016. https://doi.org/10.3389/fgene.2016.00096.

27. Houston RD, Taggart JB, Cézard T, Bekaert M, Lowe NR, Downing A, Talbot R, Bishop SC, Archibald AL, Bron JE, Penman DJ, Davassi A, Brew F, Tinch AE, Gharbi K, Hamilton A. Development and validation of a high density SNP genotyping array for Atlantic salmon (Salmo salar). BMC Genomics. 2014. https://doi.org/10.1186/1471-2164-15-90

28. Correa K, Bangera R, Figueroa R, Lhorente JP, Yáñez JM. The use of genomic information increases the accuracy of breeding value predictions for sea louse (Caligus rogercresseyi) resistance in Atlantic salmon (Salmo salar). Genet Sel Evol. 2017. https://doi.org/10.1186/s12711-017-0291-8.

29. Vallejo RL, Leeds TD, Gao G, Parsons JE, Martin KE, Evenhuis JP, Fragomeni BO, Wiens GD, Palti Y. Genomic selection models double the accuracy of predicted breeding values for bacterial cold water disease resistance compared to a traditional pedigree-based model in rainbow trout aquaculture. Genet Sel Evol. 2017. https://doi.org/10.1186/s12711-017-0293-6.

30. Robledo D, Palaiokostas C, Bargelloni L, Martínez P, Houston R. Applications of genotyping by sequencing in aquaculture breeding and genetics. Rev Aquac. 2017. https://doi.org/10.1111/raq.12193.
31. Liu S, Vallejo RL, Palti Y, Gao G, Marancik DP, Hernandez AG, Wiens GD. Identification of single nucleotide polymorphism markers associated with bacterial cold water disease resistance and spleen size in rainbow trout. Front Genet. 2015. https://doi.org/10.3389/fgene.2015.00298.

32. Mahapatra KD, Gjerde B, Sahoo PK, Saha JN, Barat A, Sahoo M, Mohanty BR, Ødegard J, Rye M, Salte R. Genetic variations in survival of rohu carp (Labeo rohita, Hamilton) after Aeromonas hydrophila infection in challenge tests. Aquaculture. 2008. https://doi.org/10.1016/j.aquaculture.2008.03.054.

33. Xiong X, Chen Y, Liu L, Wang W, Robinson NA, Gao Z. Estimation of genetic parameters for resistance to Aeromonas hydrophila in blunt snout bream (Megalobrama amblycephala). Aquaculture. 2017. https://doi.org/10.1016/j. aquaculture.2017.07.011.

34. Srisapoome $\mathrm{P}$, Chatchaiphan S, Bunnoy A, Koonawootrittriron S, Na-Nakorn $U$. Heritability of immunity traits and disease resistance of bighead catfish, Clarias macrocephalus Günther, 1864. Fish Shellfish Immun. 2019. https://doi. org/10.1016/j.fsi.2019.05.060.

35. Ødegård J, Olesen I, Dixon P, Jeney Z, Nielsen H, Way K, Joiner C, Jeney G, Ardó L, Rónyai A, Gjerde B. Genetic analysis of common carp (Cyprinus carpio) strains. II: Resistance to koi herpesvirus and Aeromonas hydrophila and their relationship with pond survival. Aquaculture. 2010. https://doi.org/ 10.1016/j.aquaculture.2010.03.017.

36. Nunes JRS, Liu S, Pértille F, Perazza CA, Villela PMS, Almeida-Val VMF, Hilsdorf AWS, Liu Z, Coutinho LL. Large-scale SNP discovery and construction of a high-density genetic map of Colossoma macropomum through genotyping-by-sequencing. Sci Rep. 2017. https://doi.org/10.1038/ srep46112.

37. Correa K, Lhorente JP, López ME, Bassini L, Naswa S, Deeb N, Genova AD, Maass A, Davidson WS, Yáñez JM. Genome-wide association analysis reveals loci associated with resistance against Piscirickettsia salmonis in two Atlantic salmon (Salmo salar L.) chromosomes. BMC Genomics. 2015. https://doi.org/ 10.1186/s12864-015-2038-7.

38. Meuwissen TH, Hayes BJ, Goddard ME. Prediction of total genetic value using genome-wide dense marker maps. Genetics. 2001; https://www.ncbi. nlm.nih.gov/pubmed/11290733.

39. Tsai HY, Robledo D, Lowe NR, Bekaert M, Taggart JB, Bron JE, Houston RD. Construction and annotation of a high density SNP linkage map of the Atlantic salmon (Salmo salar) genome. G3-Genes Genom Genet. 2016. https://doi.org/10.1534/g3.116.029009.

40. Yáñez JM, Yoshida GM, Parra Á, Correa K, Barría A, Bassini LN, Christensen KA, López ME, Carvalheiro R, Lhorente JP, Pulgar R. Comparative genomic analysis of three salmonid species identifies functional candidate genes involved in resistance to the intracellular bacterium Piscirickettsia salmonis. Front Genet. 2019. https://doi.org/10.3389/fgene.2019.00665.

41. Chang MX, Zhang J. Alternative pre-mRNA splicing in mammals and teleost fish: a effective strategy for the regulation of immune responses against pathogen infection. Int J Mol Sci. 2017. https://doi.org/10.3390/ ijms18071530.

42. Di Rienzo M, Romagnoli A, Antonioli M, Piacentini M, Fimia GM. TRIM proteins in autophagy: selective sensors in cell damage and innate immune responses. Cell Death Differ. 2020. https://doi.org/10.1038/s41418-020-0495-2.

43. Kimura T, Jain A, Choi SW, Mandell MA, Johansen T, Deretic V. TRIM-directed selective autophagy regulates immune activation. Autophagy. 2017. https:// doi.org/10.1080/15548627.2016.1154254.

44. Pandit NP, Shen YB, Xu XY, Yu HY, Wang WJ, Wang RQ, Xuan YK, Li JL. Differential expression of interleukin-12 p35 and p40 subunits in response to Aeromonas hydrophila and Aquareovirus infection in grass carp, Ctenopharyngodon idella. Genet Mol Res. 2015. https://doi.org/10.4238/2015. February.6.20.

45. Zundler S, Neurath MF. Interleukin-12: functional activities and implications for disease. Cytokine Growth F R. 2015. https://doi.org/10.1016/j.cytogfr. 2015.07.003

46. Gao F, Qu L, Yu S, Ye X, Tian Y, Zhang L, Bai J, Lu M. Identification and expression analysis of three c-type lysozymes in Oreochromis aureus. Fish Shellfish Immun. 2012. https://doi.org/10.1016/j.fsi.2012.01.031.

47. Ye X, Zhang L, Tian Y, Tan A, Bai J, Li S. Identification and expression analysis of the g-type and c-type lysozymes in grass carp Ctenopharyngodon idellus. Dev Comp Immunol. 2010. https://doi.org/10.1016/j.dci.2009.12.009.

48. Gjedrem T. Baranski. Selective breeding in aquaculture: an introduction. Dordrecht: Springer; 2009.

49. Gilmour A, Gogel B, Cullis B, Thompson R, Butler D, Cherry M, Collins D, Dutkowski G, Harding S, Haskard K. ASReml user guide release 3.0. VSN 
International Ltd., UK 275. 2009. http://www.vsni.co.uk. Accessed 19 Jan 2020.

50. Catchen JM, Amores A, Hohenlohe P, Cresko W, Postlethwait JH. Stacks: Building and genotyping loci de novo from short-read sequences. G3-Genes Genom Genet. 2011. https://doi.org/10.1534/g3.111.000240.

51. Gregg F, Derek E. Dedupe. (2019). 15 Mar 2018. https://github.com/ dedupeio/dedupe.

52. Purcell S, Neale B, Todd-Brown K, Thomas L, Ferreira MA, Bender D, Maller J, Sklar P, de Bakker PI, Daly MJ, Sham PC. PLINK: a tool set for whole-genome association and population-based linkage analyses. Am J Hum Genet. 2007. https://doi.org/10.1086/519795.

53. Marshall TC, Slate J, Kruuk LEB, Pemberton JM. Statistical confidence for likelihood-based paternity inference in natural populations. Mol Ecol. 1998 https://doi.org/10.1046/j.1365-294x.1998.00374.x.

54. Kalinowski ST, Taper ML, Marshall TC. Revising how the computer program Cervus accommodates genotyping error increases success in paternity assignment. Mol Ecol. 2007. https://doi.org/10.1111/j.1365-294X.2007.03089.x.

55. Rastas P. Lep-MAP 3: robust linkage mapping even for low-coverage whole genome sequencing data. Bioinformatics. 2017. https://doi.org/10.1093/ bioinformatics/btx494.

56. Ribeiro LB, Matoso DA, Feldberg E. Chromosome mapping of repetitive sequences in four Serrasalmidae species (Characiformes). Genet Mol Biol. 2014. https://doi.org/10.1590/S1415-47572014000100009.

57. Ouellette LA, Reid RW, Blanchard SG, Brouwer CR. LinkageMapViewrendering high-resolution linkage and QTL maps. Bioinformatics. 2018. https://doi.org/10.1093/bioinformatics/btx576.

58. Misztal I, Tsuruta S, Strabel T, Druet T, Lee D. BLUPF90 and related programs (BGF90). 7th World Congress on Genetics Applied to Livestock Production. 2002; https://doi.org/9782738010520.

59. VanRaden PM. Efficient methods to compute genomic predictions. J Dairy Sci. 2008. https://doi.org/10.3168/jds.2007-0980.

60. Wang H, Misztal I, Aguilar I, Legarra A, Muir WM. Genome-wide association mapping including phenotypes from relatives without genotypes. Genet Res (Camb). 2012. https://doi.org/10.1017/S0016672312000274.

61. Aguilar I, Misztal I, Johnson DL, Legarra A, Tsuruta S, Lawlor TJ. Hot topic: a unified approach to utilize phenotypic, full pedigree, and genomic information for genetic evaluation of Holstein final score1. J Dairy Sci. 2010. https://doi.org/10.3168/jds.2009-2730.

62. Zhang Z, Liu J, Ding X, Bijma P, de Koning DJ, Zhang Q. Best linear unbiased prediction of genomic breeding values using a trait-specific marker-derived relationship matrix. PLoS One. 2010. https://doi.org/10.1371/ journal.pone.0012648.

63. Turner SD. qqman: an R package for visualizing GWAS results using $\mathrm{Q}-\mathrm{Q}$ and Manhattan plots. biorXiv. https://doi.org/10.1101/005165.

64. Lourenco D, Legarra A, Tsuruta S, Masuda Y, Aguilar I, Misztal I. Single-step genomic evaluations from theory to practice: using SNP chips and sequence data in BLUPF90. Genes. 2020. https://doi.org/10.3390/ genes11070790

\section{Publisher's Note}

Springer Nature remains neutral with regard to jurisdictional claims in published maps and institutional affiliations.

Ready to submit your research? Choose BMC and benefit from:

- fast, convenient online submission

- thorough peer review by experienced researchers in your field

- rapid publication on acceptance

- support for research data, including large and complex data types

- gold Open Access which fosters wider collaboration and increased citations

- maximum visibility for your research: over $100 \mathrm{M}$ website views per year

At BMC, research is always in progress.

Learn more biomedcentral.com/submissions 